\title{
ANÁLISE ESPACIAL DE RISCO PARA LEPTOSPIROSE NO MUNICÍPIO DE JOINVILLE (SC)
}

\section{SPATIAL ANALYSIS OF RISK TO LEPTOSPIROSIS IN THE MUNICIPALITY OF JOINVILLE (SC)}

\author{
Ariadine Monique Prado \\ Eng. Ambiental e Sanitarista, ENGETEC - UNIVILLE \\ ariadine.prado@gmail.com \\ Celso Voos Vieira \\ Dr. Geografia, ENGETEC - UNIVILLE \\ celso.v@univille.br
}

\begin{abstract}
RESUMO
A leptospirose é uma das zoonoses de maior preocupação em todo mundo, pois apresenta vasta distribuição geográfica, tendo sido evidenciada em mais da metade dos países, sendo particularmente prevalente nas Américas. O presente estudo teve como objetivo analisar a distribuição espacial da leptospirose, no município de Joinville/SC no período de 2007 a 2017. Para a análise estatística foram adotadas técnicas de análise descritiva, de normalidade, de correlação e de agrupamento, envolvendo os 43 bairros do município, com cinco variáveis descritoras. O presente estudo indicou que a maior incidência de casos da doença em Joinville está relacionada às áreas com baixa cobertura de rede coletora de esgoto, baixa renda média, média a alta densidade demográfica e áreas suscetíveis à inundação. Os dois bairros com o maior número de casos, Vila Nova e Pirabeiraba, foram notadamente as regiões urbanas caracterizadas por extensas propriedades alagadas voltadas ao cultivo de arroz irrigado. A análise de agrupamento classificou o perímetro urbano em cinco grupos de bairros. Os grupos com maior número de casos localizavam-se em áreas próximas de manguezal e áreas marginais da cidade, com alta suscetibilidade à inundação e alta densidade demográfica. A identificação desses locais foi de extrema importância e possibilita uma promissora abordagem para uma melhor implementação de políticas públicas no combate as doenças de veiculação hídrica.
\end{abstract}

Palavras-chave: Estatística. Geoprocessamento. Saúde pública. Vulnerabilidade social. Zoonose.

\begin{abstract}
Leptospirosis is one of the major concern zoonoses in the world, as it has a wide geographic distribution, having been evidenced in more than half of the countries, being particularly prevalent in the Americas. The present study aimed to analyze the spatial distribution of leptospirosis in the city of Joinville / SC from 2007 to 2017. For the statistical analysis, descriptive analysis, normality, correlation and clustering techniques were adopted, involving the 43 neighborhoods of the municipality, with five descriptive variables. The present study indicated that the highest incidence of cases of the disease in Joinville is related to areas with low coverage of the sewage network, low middle income and medium to high population density and areas susceptible to flooding. The two neighborhoods with the highest number of cases, Vila Nova and Pirabeiraba, were notably the urban regions characterized by extensive flooded properties aimed at the cultivation of irrigated rice. The groups with the highest number of cases were located in areas close to mangroves and marginal areas of the city, with high susceptibility to flooding and high demographic density. The identification of these places was extremely important and allows a promising approach for a better implementation of public policies to combat waterborne diseases.
\end{abstract}

Key words: Statistic. Geoprocessing. Public health. Social vulnerability. Zoonosis. 


\section{INTRODUÇÃO}

A leptospirose é uma doença causada por espiroquetas do gênero Leptospira que atinge tanto animais domésticos como silvestres. A enfermidade é transmitida a esses animais e ao homem pela urina de roedores domésticos e silvestres, que são portadores naturais da infecção (COURA, 2008; BRASIL, 2014;). É uma zoonose de grande preocupação em todo mundo, por apresentar vasta distribuição geográfica, sendo evidenciada em mais da metade dos países, e particularmente prevalente na América Latina e no Caribe (GENOVEZ, 2009). A sua ocorrência possui estreita relação com os fatores ambientais, apresentando alta dependência espacial identificada entre as variáveis ambientais, socioeconômicas e epidemiológicas (GONÇALVES et al., 2016). A bactéria pode permanecer em água limpa por aproximadamente 150 dias, todavia não toleram alto nível de salinidade, baixo $\mathrm{pH}$ e competição bacteriana em meios contaminados. Desse modo, a água pluvial é o meio ideal para a sua sobrevivência (GENOVEZ, 2009).

Diante do exposto, as áreas com ocorrência de inundações (CESA \& DUARTE, 2010; GONÇALVES et al., 2016) e ausência ou precariedade no sistema de coleta e tratamento de esgotamento sanitário (PAIVA \& SOUZA, 2018) propiciam a disseminação e a persistência do agente causal no ambiente, facilitando a ocorrência de surtos.

No Brasil entre 2000 e 2019 (até 16/07/2019), conforme o Sistema de Informação de Agravos de Notificação (SINAN) do Ministério da Saúde, foram notificados 72.176 casos de leptospirose. Sendo que as duas regiões com o maior número de casos foram região Sudeste e Sul. Entre os estados do Sul, Santa Catarina foi o que registrou o maior número de notificações e o município catarinense com o maior número nesse período foi Joinville.

Uma das formas de analisar a relação da sociedade, do meio ambiente e da saúde pública ocorre pela espacialização da distribuição das doenças. Segundo Chiaravalloti-Neto (2017) o Geoprocessamento é uma área do conhecimento que permite a implementação de técnicas geoestatísticas que podem melhor descrever os fenômenos espacialmente (SANTOS et al., 2017) e mostra-se como uma promissora abordagem para a área da vigilância (CALDAS et al., 2019).

De acordo com Bailey (2001) os mapas de incidência de doenças sempre desempenharam um papel descritivo chave na epidemiologia espacial. São úteis para diversos fins, tais como: identificação de áreas com suspeita de elevação do risco de uma doença, auxiliando na formulação de hipóteses sobre a etiologia da doença e avaliando necessidades potenciais de variação geográfica em estudos de acompanhamento, medidas preventivas ou outras formas de alocação de recursos de saúde.

Levando-se em consideração vários fatores de risco, suas relações com a ocorrência da leptospirose e as características do município de Joinville, o presente estudo teve por objetivo analisar a distribuição espacial dessa importante zoonose, no período de 2007 a 2017 no referido espaço geográfico. A presente abordagem ainda pretende contribuir para o desenvolvimento de metodologias de análise espacial de incidência e na geração de informações válidas para políticas públicas de monitoramento e controle de doenças.

\section{METODOLOGIA}

\section{Fonte de dados e variáveis de interesse}

Os dados de leptospirose foram obtidos junto à Secretaria de Saúde de Joinville e extraídos do Sistema de Informação de Agravos de Notificação (SINAN), no período de 2007 a 2017. Os dados foram cedidos por bairro, para não expor a população afetada, com um total de 493 notificações válidas que continham informações de localização (bairro) e ano de ocorrência. Esse valor representou o universo deste estudo.

As demais variáveis adotadas para explicar a ocorrência dos casos de leptospirose foram: percentual de inundação, percentual de rede coletora de esgoto, densidade demográfica e renda média de cada bairro do município.

As áreas de inundação foram obtidas pela análise da mancha de inundação, confeccionada pela Secretaria de Estado da Defesa Civil de Joinville. Os dados do percentual da rede coletora de esgoto ativa foram fornecidos pela Companhia Águas de Joinville (CAJ). Essas informações vetoriais foram obtidas no Sistema de Informações Municipais Georreferenciadas - SIMGeo da 
Prefeitura Municipal de Joinville (https://geoprocessamento.joinville.sc.gov.br/). Os dados de densidade demográfica e renda mensal média de cada bairro foram obtidos no periódico Joinville Bairro a Bairro, confeccionado pela Secretaria de Planejamento Urbano e Desenvolvimento Sustentável - SEPUD (SEPUD, 2017). Todas as informações cartográficas foram trabalhadas no software ArcGis 10.1, com a utilização da projeção Universal Transversa de Mercator (UTM), datum SIRGAS2000.

\section{Análises Estatísticas}

As análises estatísticas foram divididas em duas partes. Primeiramente foi realizada a análise descritiva com o objetivo de descrever, resumir e compreender os dados de distribuição das variáveis usando medidas de tendência central (média e mediana) e medidas de dispersão (variância, desvio padrão e a amplitude interquartil). Em seguida foi feita a análise de normalidade com a aplicação do teste de Kolmogorov-Smirnov e Shapiro-Wilk. Posteriormente foi executada uma análise de correlação de Spearman (visto que os dados são não-paramétricos) adotando-se um $p$ de 0,05 em virtude dos dados não possuírem uma distribuição conjunta normal.

A segunda parte consistiu na análise de agrupamento (cluster) com objetivo de avaliar as similaridades entre as amostras, de modo a redefini-las em grupos. De modo a agrupar os bairros foram considerados os seguintes descritores: número de casos, percentual de inundação, percentual de rede de esgoto, renda mensal média e densidade demográfica. Os descritores foram analisados segundo o quadrado da distância euclidiana e a estratégia de agrupamento adotada foi a média ponderada de grupos pareados (WPGMA), para montar uma árvore hierárquica de similaridade entre os bairros. Os bairros com valores de distância de ligação baixa (próxima de 0), indicam que os mesmos possuem variáveis equivalentes e são parecidos. Os bairros com características diferentes possuem dist6ancia de ligação alta (próxima de 100). Valores mais altos de ligação indicam que os bairros e grupos de bairros formados, possuem valores das variáveis preditoras muito discrepantes entre si, ou seja, são bairros muito diferentes.

\section{RESULTADOS E DISCUSSÃO}

\section{Leptospirose em Joinville}

De acordo com o Apêndice 1, nesse período foram registradas 493 notificações da doença na cidade. Dos 43 bairros do município, 8 representaram cerca de $50 \%$ do total de casos registrados, sendo eles: Pirabeiraba com 54 casos (10,95\%), seguido pelos bairros Vila Nova com 46 casos $(9,33 \%)$, Aventureiro com 30 casos $(6,08 \%)$, Fátima com 25 casos $(5,07 \%)$, Paranaguamirim com 24 casos $(4,86 \%)$, Jardim Paraíso com 23 casos $(4,66 \%)$, Boa Vista com 23 casos $(4,66 \%)$ e Itaum com 19 casos $(3,85 \%)$. O bairro Zona Industrial Tupy não registrou nenhum caso da doença, enquanto 6 bairros registraram apenas uma ocorrência, sendo eles: São Marcos, Profipo, Centro, Bucarein, Atiradores e Zona Industrial Norte.

A Figura 1 é um mapa que ilustra a distribuição dos casos de leptospirose em Joinville no intervalo de 2007 a 2017. A zona oeste da cidade contempla os bairros com menor ocorrência de leptospirose, com exceção aos bairros Pirabeiraba e Vila Nova, que possuem os maiores valores de ocorrência. A zona leste da cidade, nas proximidades da baía da Babitonga, os bairros possuem números intermediários de ocorrência de leptospirose. De maneira geral, observa-se um aumento dos casos de leptospirose por bairro no sentido oeste-leste, com os Pirabeiraba e Vila Nova se comportando como anomalias.

\section{Mancha de inundação}

A Figura 2 ilustra o mapa de mancha de inundação do município. Nota-se que todos os bairros de Joinville são atingidos pela mancha, sendo o bairro Jardim Sofia o que possui o maior percentual de área afetada, com $93,38 \%$ e o bairro Santa Catarina o menos afetado, com $0,86 \%$. As regiões mais afetadas estão associadas às áreas planas, com altitude inferior a $10 \mathrm{~m}$ que configuram as amplas planícies de inundação de rios meandrantes. Ressalta-se a importância da Baía da Babitonga que banha as regiões Nordeste, Leste e Sudeste da cidade, que exerce uma grande 
influência nas inundações recorrentes no município, em virtude do regime de maré, alinhado com os altos índices pluviométricos da região.

\section{Cobertura de esgoto}

A Figura 3 apresenta o mapa de cobertura da rede esgoto ativa nos bairros de Joinville. Atualmente, dos 43 bairros do município 23 possuem algum percentual de cobertura de rede de esgoto ativa, o que representa pouco mais de $50 \%$ dos bairros da cidade, concentrados em quase sua totalidade na região central do município. Porém, é importante ressaltar que dentre estes 23 bairros, nenhum possui $100 \%$ de cobertura. O bairro Centro possui a maior porcentagem de cobertura da rede de esgoto ativa, com $99,55 \%$ e o bairro Zona Industrial Norte possui apenas $2,41 \%$. Os demais 20 bairros não possuem cobertura de rede de esgoto ativa.

\section{Renda média}

A Figura 4 exibe o mapa de distribuição de renda média, em salários mínimos, dos bairros de Joinville. Dos 43 bairros do município, cerca de $80 \%$ possui renda média entre 1 e 3 salários mínimos. O bairro de maior renda média é o Atiradores com 6,46 salários mínimos e o bairro com menor renda média é o Ulysses Guimarães, com 1,14. A maior concentração de renda está localizada nos bairros próximos à região central de Joinville, caracterizando essa área como a região de maior poder aquisitivo da cidade e os bairros marginais com a menor renda média.

\section{Densidade demográfica}

A Figura 5 apresenta o mapa de densidade demográfica dos bairros de Joinville. Os bairros com menor densidade demográfica situam-se na porção oeste e as maiores densidades situam-se nos bairros próximos à baía da Babitonga, na porção leste do município.

De acordo com o Apêndice 1, do total de 43 bairros do município, $60 \%$ apresentam densidade demográfica entre 2.000 e $6.000 \mathrm{hab} / \mathrm{km}^{2}$. O bairro de maior densidade é o Comasa com 7.981 $\mathrm{hab} / \mathrm{km}^{2}$ e o de menor densidade o bairro Zona Industrial Tupy com $48 \mathrm{hab} / \mathrm{km}^{2}$. As áreas de menor densidade identificadas estão situadas em bairros estruturados para a implantação de indústrias e por esse motivo de menor interesse para moradia. 
Figura 1 - Distribuição dos casos de Leptospirose em Joinville entre 2007 e 2017.

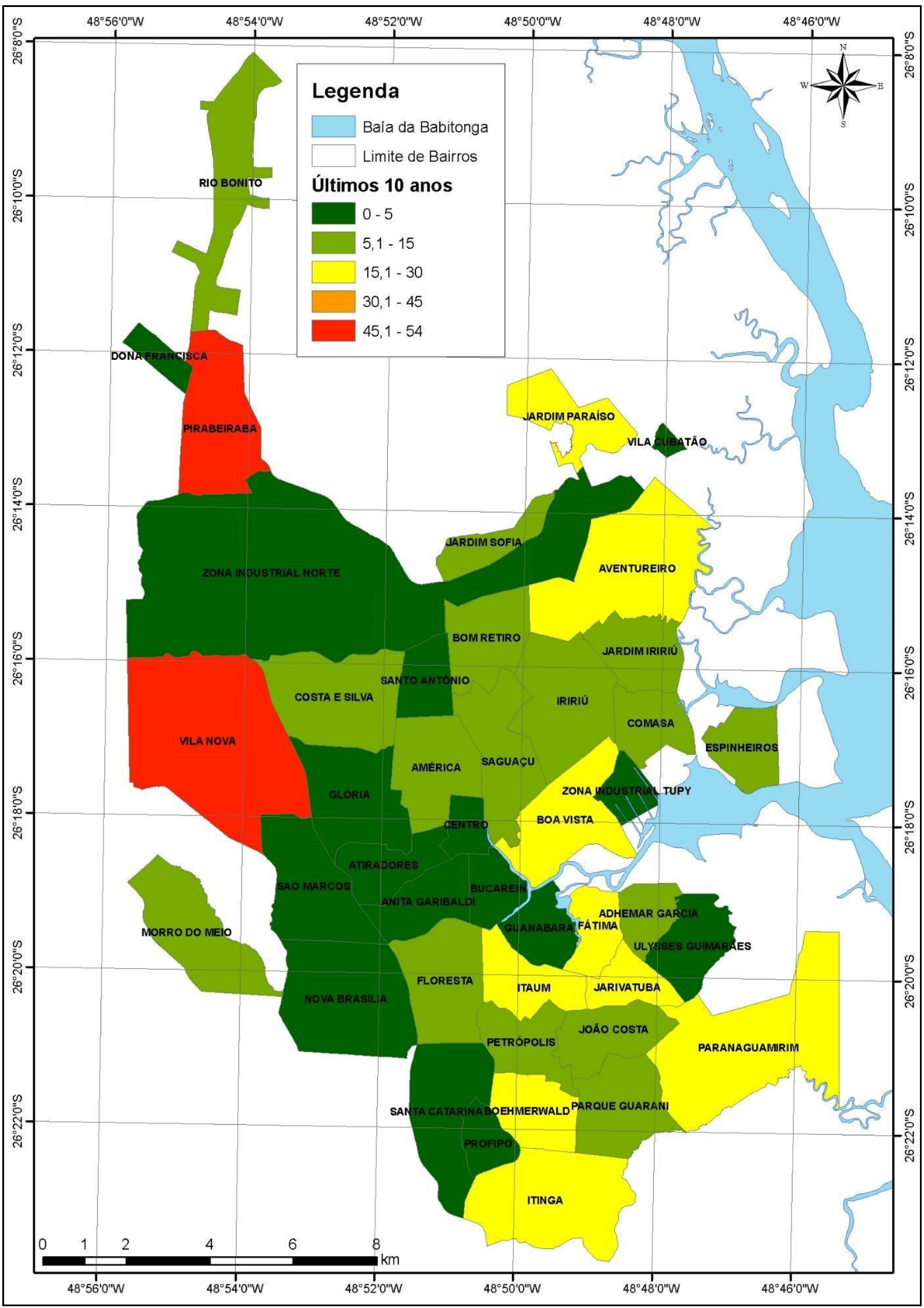


Figura 2 - Mancha de inundação dos bairros de Joinville.

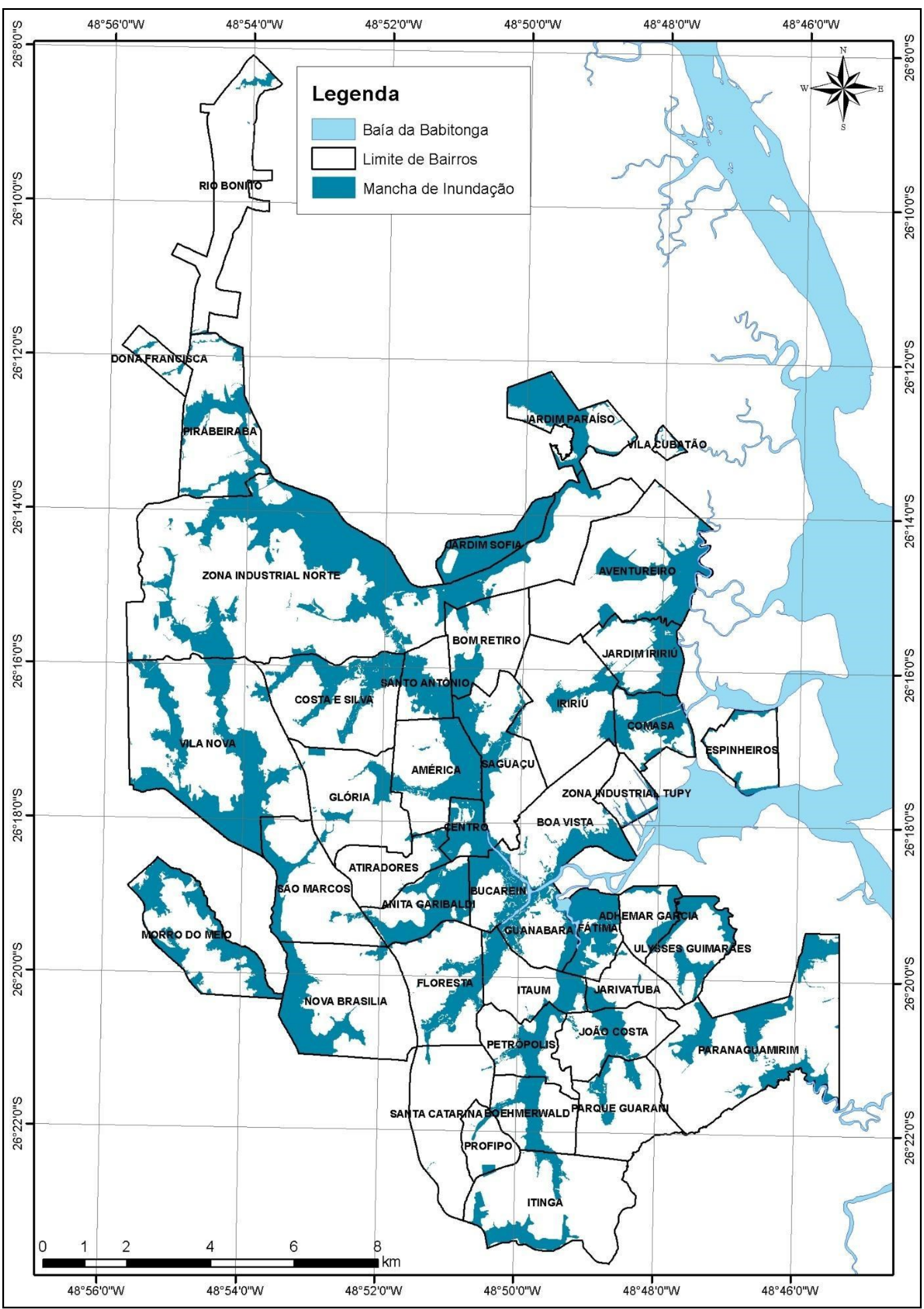


Figura 3 - Cobertura da rede coletora de esgoto ativa nos bairros de Joinville.

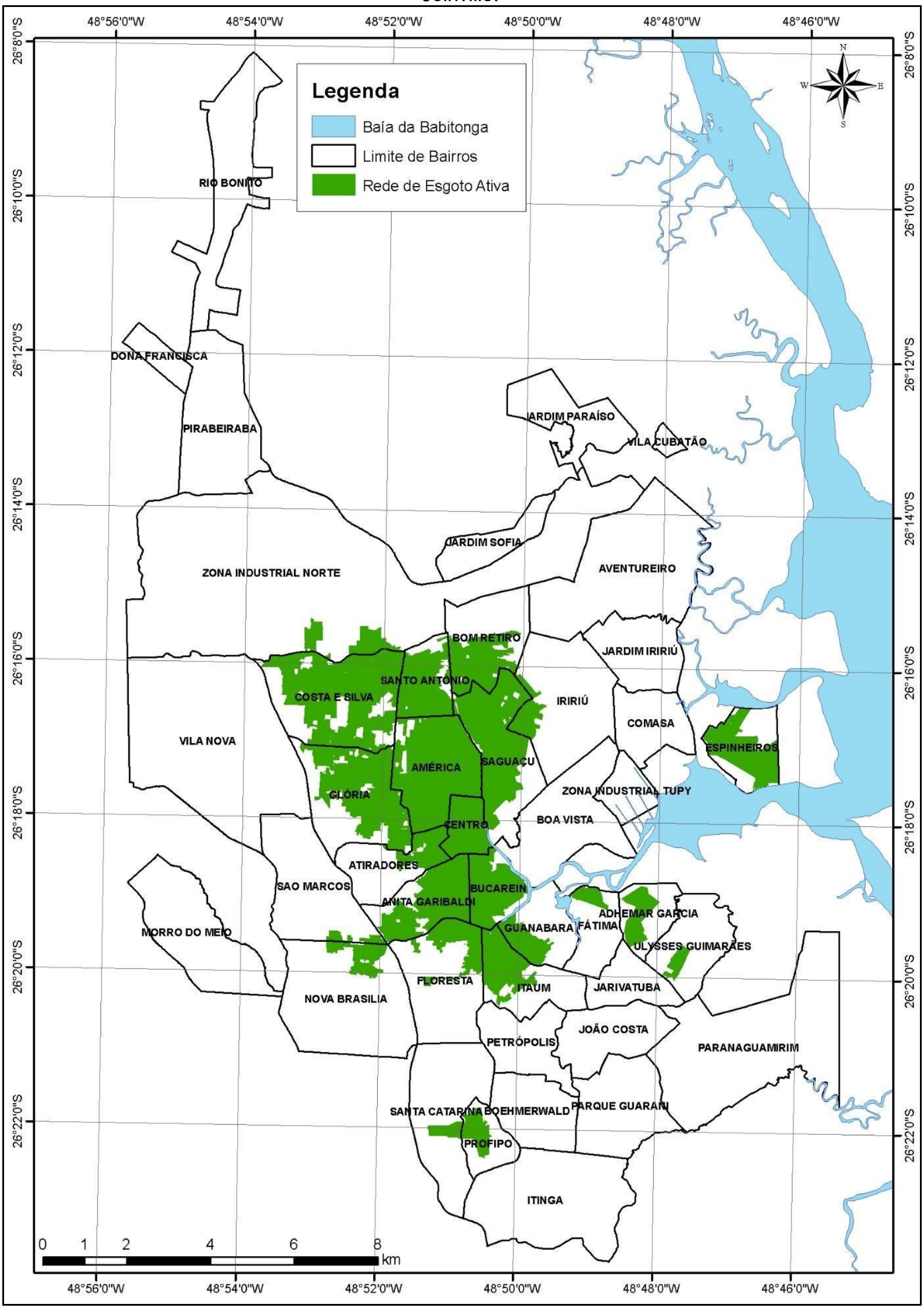


Figura 4 - Renda média dos bairros de Joinville em salários mínimos.

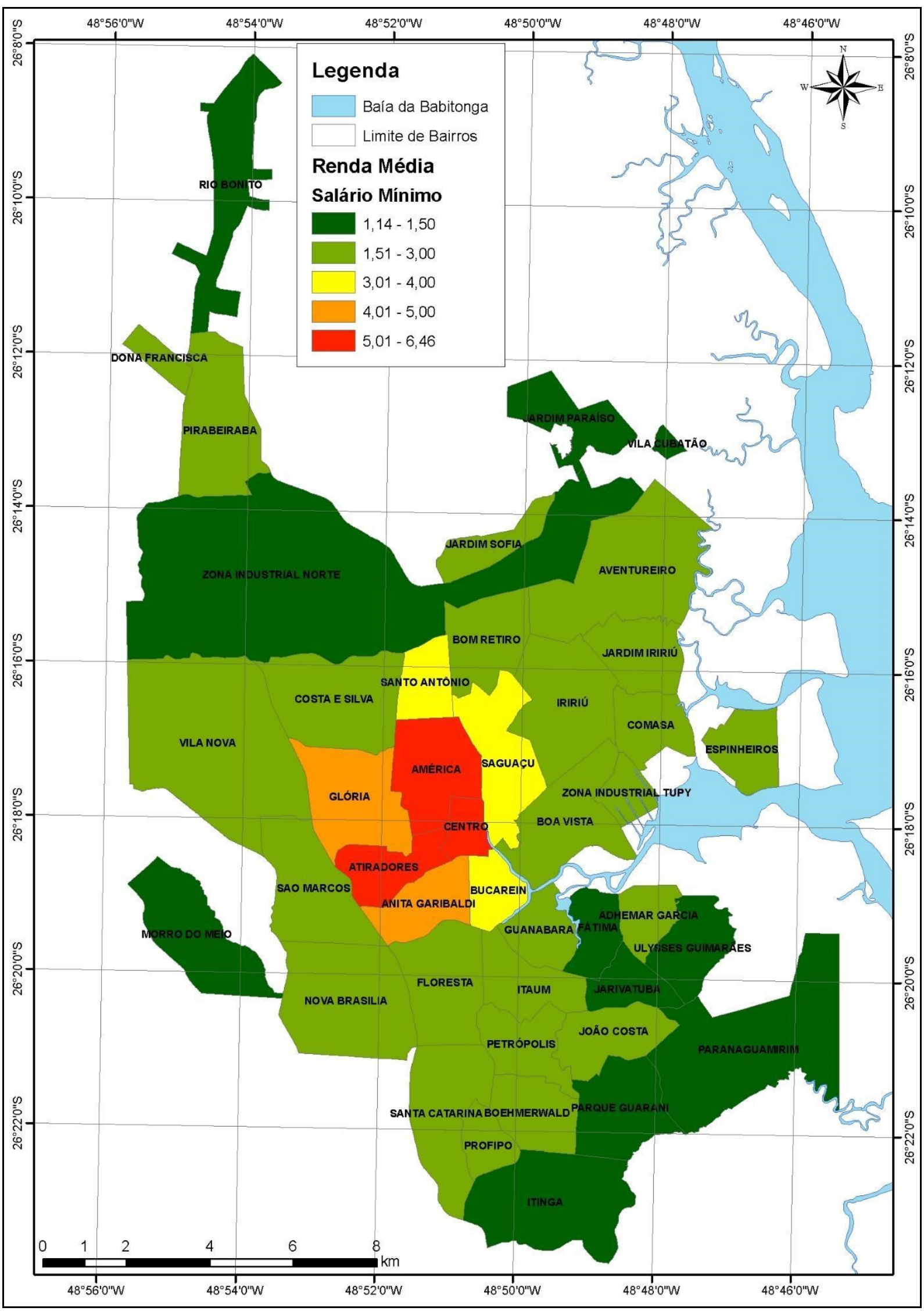


Figura 5 - Densidade demográfica dos bairros de Joinville $\left(\mathrm{hab} / \mathrm{km}^{2}\right)$.

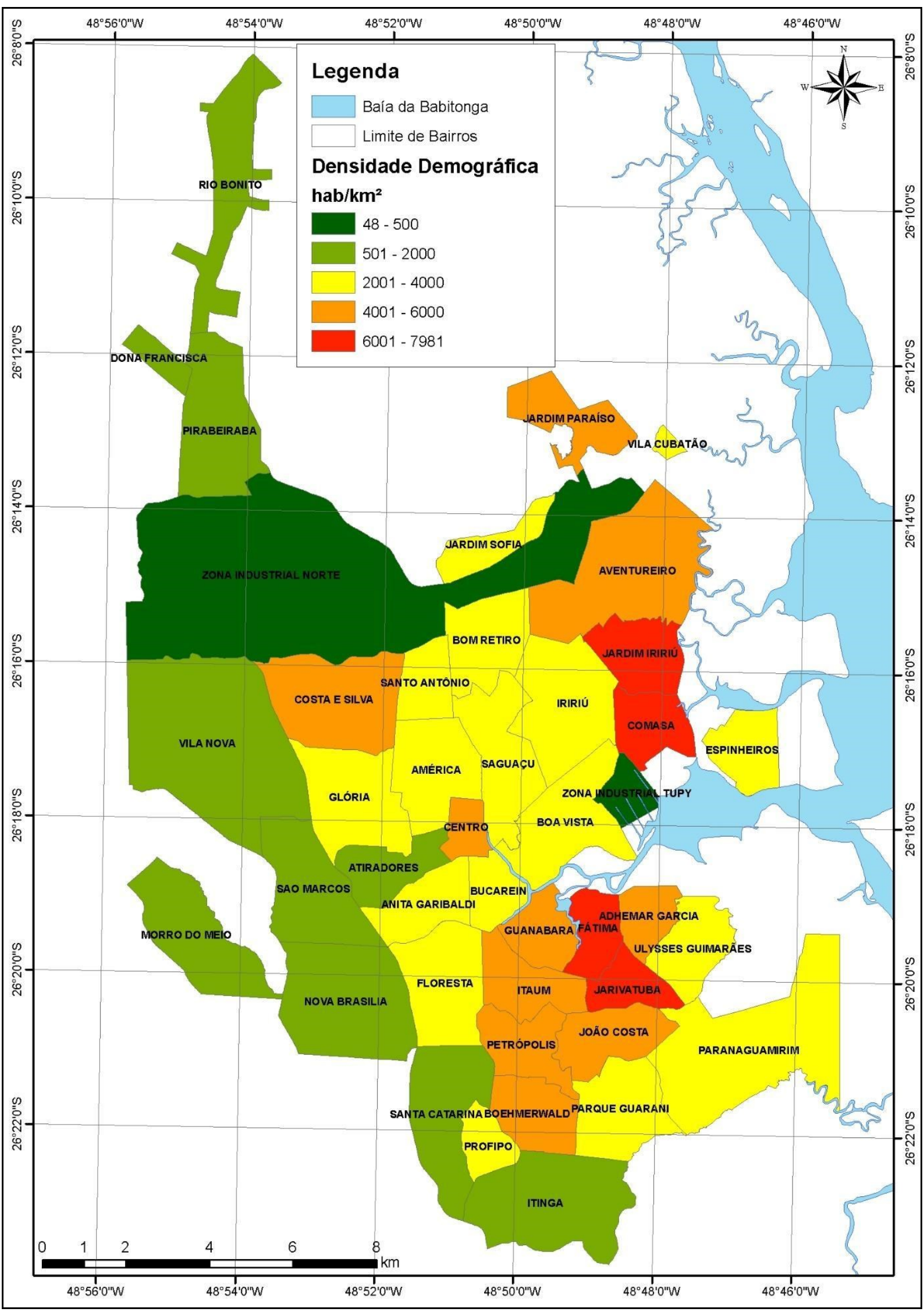




\section{Estatística Descritiva}

A tabela 1 apresenta o resumo dos dados de distribuição das variáveis, usando medidas de tendência central e medidas de dispersão.

Tabela 1- Medidas de tendência central e de dispersão das variáveis.

\begin{tabular}{c|c|c|c|c|c} 
Variáveis & Média & Mediana & Mínimo & Máximo & $\begin{array}{c}\text { Coeficiente de } \\
\text { Variação (\%) }\end{array}$ \\
\hline Casos & $11,47 \pm 11,57$ & 8,00 & 0,00 & 54,00 & 100,88 \\
\hline \% de Inundação & $31,41 \pm 21,19$ & 26,59 & 0,86 & 93,38 & 67,47 \\
\hline \% de Rede de Esgoto & $23,04 \pm 32,13$ & 3,74 & 0,00 & 99,55 & 139,47 \\
\hline $\begin{array}{c}\text { Renda Média } \\
\text { (salários mínimos) }\end{array}$ & $2,27 \pm 1,37$ & 1,67 & 1,14 & 6,46 & 60,23 \\
\hline $\begin{array}{c}\text { Densidade Demográfica } \\
\text { (hab/km²) }\end{array}$ & $\begin{array}{c}3.304,98 \pm \\
1.966,17\end{array}$ & $3.042,00$ & 48,00 & $7.981,00$ & 59,49
\end{tabular}

Segundo Fonseca e Martins (2012), considera-se que dados com coeficiente de variação menor que $15 \%$ indicam baixa dispersão, entre $15 \%$ e $30 \%$ média dispersão e maior que $30 \%$ alta dispersão. Observa-se que para as variáveis analisadas na tabela 1 todos os coeficientes de variação apresentaram-se acima de 30\%, caracterizando alto grau de dispersão.

A média de casos no município no período de estudo foi 11,47 , com um valor máximo de 54 e um desvio padrão de 11,57 , com variabilidade de $100,88 \%$. Para percentual de inundação a média foi 31,41 , sendo 0,86 o valor mínimo e 93,38 o máximo, com um desvio padrão de 21,19 e variabilidade de $67,47 \%$. Para percentual de atendimento pela rede coletora de esgoto a média foi 23,04 , com um desvio padrão de 32,13 e variabilidade de $139,47 \%$. A média da renda média de salários foi 2,27 , com um desvio padrão de 1,37 e variabilidade de $60,23 \%$. Para densidade demográfica a média foi de 3.304,98, com um desvio padrão de 1966,17 e coeficiente de variação de 59,49\%.

\section{Coeficiente de correlação de Spearman}

A tabela 2 apresenta os resultados dos coeficientes de correlação, entre as variáveis adotadas para avaliação da incidência dos casos de leptospirose, na área urbana de Joinville.

Tabela 2 - Coeficiente de correlação de Spearman para as variáveis descritoras.

\begin{tabular}{c|c|c|c|c|c} 
Variáveis & $\begin{array}{c}\text { Número de } \\
\text { Casos }\end{array}$ & $\begin{array}{c}\text { \% de } \\
\text { Inundação }\end{array}$ & $\begin{array}{c}\text { \% de } \\
\text { Esgoto }\end{array}$ & $\begin{array}{c}\text { Renda Média } \\
\text { (salários } \\
\text { mínimos) }\end{array}$ & $\begin{array}{c}\text { Densidade } \\
\text { Demográfica } \\
\text { (hab/km) }\end{array}$ \\
\hline Número de Casos & 1 & 0,17 & $-\mathbf{0 , 4 2 *}$ & $\mathbf{- 0 , 3 3}^{*}$ & $\mathbf{0 , 4 3}^{*}$ \\
\hline \% de Inundação & - & 1 & 0,19 & 0,035 & 0,11 \\
\hline \% de Esgoto & - & - & 1 & $\mathbf{0 , 6 7}$ & $-0,13$ \\
\hline $\begin{array}{c}\text { Renda Média } \\
\text { (salários mínimos) }\end{array}$ & - & - & - & 1 & 1
\end{tabular}

O sinal indica se a correlação é positiva ou negativa. Células destacadas com asterisco possuem $p<0,05$.

Os dados de correlação indicam que a maior incidência de casos da doença em Joinville está relacionada com as áreas de baixa cobertura de rede de esgoto, baixa renda média e alta densidade demográfica. De acordo com Mello et al. (2017), as características físicas da bacia hidrográfica do Rio Cachoeira, associada aos altos índices pluviométricos e a intensa ocupação antrópica, propiciam o desenvolvimento de regiões de alta vulnerabilidade a eventos hidrológicos extremos, como inundação e deslizamento. Os fatores identificados caracterizam o perímetro urbano de Joinville como favorável para o desenvolvimento de regiões de vulnerabilidade social e suscetíveis ao desenvolvimento de doenças. 
Observou-se ainda uma correlação positiva entre o percentual de cobertura de esgoto e a renda média, indicando que os bairros com maior poder aquisitivo possuem maior cobertura de rede de esgoto. Deve ser ressaltado ainda que os bairros com maior percentual de inundação possuem alta densidade demográfica. Nesse sentido, observou-se em Joinville a ocorrência de áreas suscetíveis à inundação e à exposição e concentração da população de baixa renda em áreas extremamente propícias ao desenvolvimento de doenças transmitidas por vetores. Segundo Pelissari et al. (2011) e Vasconcellos et al. (2012) nas áreas urbanas a maioria dos estudos associa a leptospirose às condições socioeconômicas da população e às condições sanitárias.

Em Joinville, os dois bairros com maior número de casos foram Pirabeiraba e Vila Nova. Os bairros possuem baixa renda média, ausência de rede de esgoto e áreas suscetíveis à inundação, todavia, ambos os bairros possuem baixa densidade demográfica. $O$ grande número de casos pode ser explicado pelas tradições culturais, visto que ambos os bairros ainda possuem expressiva atividade agrícola e pecuária, desenvolvida no perímetro urbano. Em ambos os bairros é comum a ocorrência de edificações para o armazenamento de insumos agrícolas ou para a criação de animais para a produção da grãos (arroz irrigado). Essas características podem atrair roedores e intensificar a proliferação da leptospirose. Santos et al. (2018) em uma análise de infestação de roedores concluiu que a maior ocorrência de roedores e da leptospirose está associada com a proximidade de valas e canais abertos e de fundos de vale, ou seja, áreas com possibilidade de acumulação de água. Ressalta-se que, ambos os bairros estão inseridos em uma planície fluvial alagada para a produção de arroz irrigado, com amplas áreas de cultivo. Esses fatores caracterizam os dois bairros como parte do grupo de maior risco de incidência da doença, de acordo com Coura (2008).

É possível observar também a relação entre a densidade demográfica e as áreas de inundação, o que caracteriza o histórico de ocupação de Joinville, com amplo adensamento urbano em áreas de fragilidade ambiental, como planícies de inundação e áreas de manguezal. Esta situação foi determinada em boa parte, pela trajetória industrial de Joinville, que motivou a vinda de um grande número de pessoas em busca de trabalho, que com pouco recursos passaram a ocupar extensas áreas marginais com alta suscetibilidade à inundação (TEBALDI, 2008; CAMPIOLI \& VIEIRA, 2019).

Verificou-se também que a maior parte das áreas com maior cobertura de esgoto estão centralizadas nos bairros onde a população dispõe de maior poder aquisitivo. Fatores que alinhados podem explicar a baixa incidência da leptospirose nessas áreas.

Em um estudo realizado no estado de Pernambuco (VASCONCELOS et al., 2012), foi observado que as áreas de maior incidência de leptospirose coincidiram com os locais com cobertura de esgotamento sanitário precário e de maior densidade demográfica. Diferentes estudos realizados no município do Rio de Janeiro, por Carvalho et al. (2017), Chaiblich et al. (2017) e Oliveira et al. (2012), destacaram também as condições precárias de moradia e saneamento, riscos de inundação e ocupação desordenada como fatores preponderantes para as altas taxas de incidência da leptospirose no município. Segundo Paula (2005) em análise climato-geográfica de manifestação da leptospirose no Brasil, Paraná e Curitiba, a alta densidade de habitantes e a elevada produção de lixo, aliadas aos problemas de saneamento, sobretudo nas áreas de sub-habitações, constituem elementos favoráveis à proliferação dos principais reservatórios.

De acordo com dados divulgados pela Companhia Águas de Joinville (empresa pública de saneamento básico) o município de Joinville possui atualmente $98,91 \%$ da população com atendimento de água tratada e apenas $33,71 \%$ com atendimento de esgoto. Com possível ampliação para $48 \%$ no ano de 2020 (Jornal)

Guerra \& Cunha (2006) destacaram que, nas situações em que o crescimento urbano não é acompanhado pela ampliação equitativa dos investimentos em infraestrutura e democratização do acesso aos serviços urbanos, há uma tendência para que as desigualdades socioespaciais sejam produzidas ou mesmo se agravem.

\section{Análise de Agrupamento}

A figura 6, resultante da análise de agrupamento classificou os bairros do município de Joinville em 5 grupos, levando em consideração a similaridade entre as variáveis adotadas, sendo elas: número de casos, percentual de inundação, percentual de cobertura de esgoto, renda média em salários mínimos e densidade demográfica. 
Figura 6 - Grupos de bairros formados de acordo com a semelhança das variáveis adotadas.

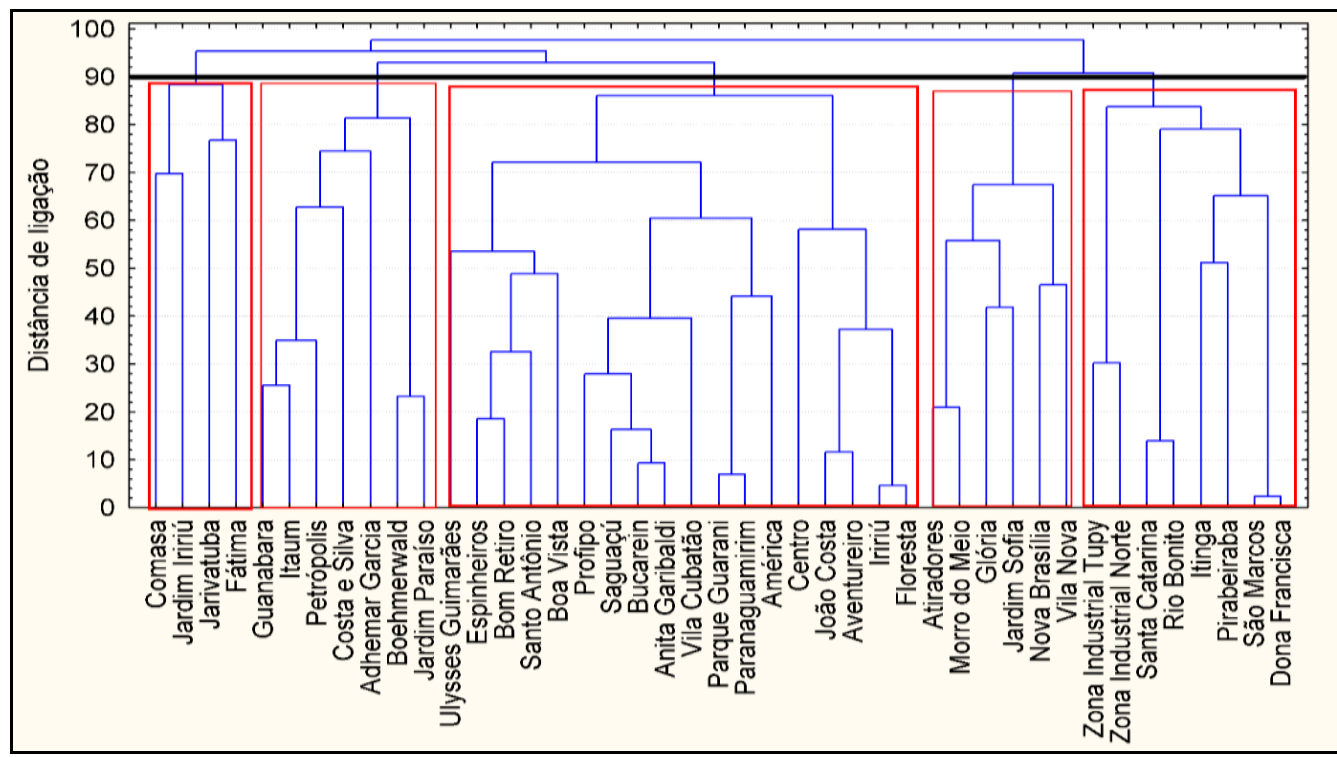

A distância de ligação indica o grau de similaridade das variáveis preditoras dos bairros, com a subsequente formação de grupos hierárquicos. A distância de corte adotada foi de $90 \mathrm{com}$ a formação de cinco grupos de bairros. Observa-se que o grupo 1, da esquerda para a direita, tem uma maior similaridade com os grupos 2 e 3 , enquanto o grupo 4 possui uma maior similaridade com o grupo 5. Na tabela 3, encontram-se os valores médios e desvios-padrão das variáveis descritoras adotadas para a formação de grupos de bairros similares.

Tabela 3 - Variáveis descritoras dos grupos de bairros.

\begin{tabular}{|c|c|c|c|c|c|}
\hline Variáveis & Grupo 1 & Grupo 2 & Grupo 3 & Grupo 4 & Grupo 5 \\
\hline $\mathrm{N}^{\circ}$ de bairros & 4 & 7 & 18 & 6 & 8 \\
\hline Casos & $17,00 \pm 5,48$ & $14,14 \pm 6,62$ & $9,28 \pm 8,57$ & $12,17 \pm 16,88$ & $10,75 \pm 18,23$ \\
\hline Inundação & $47,05 \pm 26,75$ & $36,28 \pm 11,06$ & $31,29 \pm 20,26$ & $37,35 \pm 30,63$ & $15,15 \pm 10,99$ \\
\hline Esgoto & $2,97 \pm 5,93$ & $25,83 \pm 28,28$ & $38,11 \pm 38,61$ & $16,89 \pm 25,8$ & $1,31 \pm 1,89$ \\
\hline $\begin{array}{c}\text { Renda Média } \\
\text { (salários } \\
\text { mínimos) } \\
\end{array}$ & $1,46 \pm 0,07$ & $1,75 \pm 0,47$ & $2,70 \pm 1,60$ & $2,83 \pm 2,08$ & $1,77 \pm 0,34$ \\
\hline $\begin{array}{c}\text { Densidade } \\
\text { Demográfica } \\
\text { (hab/km) }\end{array}$ & $\begin{array}{r}7284,00 \\
\pm 645,60\end{array}$ & $\begin{array}{r}5151,57 \\
\pm 441,97\end{array}$ & $\begin{array}{r}3323,78 \\
\pm 519,79\end{array}$ & $\begin{array}{r}1960,00 \\
\pm 189,42\end{array}$ & $\begin{array}{c}666,13 \\
\pm 447,55\end{array}$ \\
\hline
\end{tabular}

Desta maneira, os grupos de bairros podem ser entendidos da seguinte forma:

Grupo 1 - Apresenta as maiores médias de percentual de inundação e densidade demográfica, aliada a menor média de renda e a segunda menor média de percentual de rede de esgoto. Fatores que alinhados explicam a maior média de casos do município, levando em consideração que populações que vivem em regiões com pouca infraestrutura, alta densidade e baixa renda correm maior risco.

Grupo 2 - Apresenta a segunda maior média para percentual de cobertura de esgoto e a segunda maior densidade demográfica, aliadas a terceira maior média de percentual de inundação e segunda menor média de renda. Demonstra que apesar de dispor de maior infraestrutura básica que o grupo 1 , as demais variáveis ainda possuem peso sob a ocorrência da leptospirose, tendo em vista que o grupo 2 registrou a segunda maior média de casos. 
Grupo 3 - Apresenta-se como o grupo mais heterogêneo em função da maior quantidade de bairros. Nota-se que o grupo ostenta a maior média para percentual de cobertura de esgoto e a segunda maior para a renda média. Apresenta também a segunda menor média para percentual de inundação e possui valores medianos de densidade demográfica, situando-se em terceiro lugar entre os cinco grupos. Esse grupo de bairros dispõe de melhor infraestrutura, alto poder aquisitivo e moradia em localização mais favorável, fatores que diminuem a ocorrência da doença, levando em consideração que o grupo 3 registrou a menor média de casos.

Grupo 4 - Denota a maior média de renda, a segunda menor média de densidade demográfica, percentual de cobertura de esgoto mediano, porém com a segunda maior média de inundação. Um maior poder aquisitivo da população residente nesses bairros, associado a uma infraestrutura de rede de esgoto com percentuais medianos e baixa densidade demográfica pode explicar uma ocorrência menor de casos, apesar do alto percentual de inundação.

Grupo 5 - Este grupo exibe a menor média para percentual de cobertura de esgoto da cidade, assim como baixo percentual de área inundada, os bairros possuem baixa densidade demográfica, muito em função das zonas industriais, possuem renda média com valores medianos. Devido a baixa densidade demográfica, os bairros do grupo 5 possuem a segunda menor média de casos.

A Figura 7 apresenta um mapa com a formação de cinco grupos de bairros classificados conforme a análise de agrupamento. O mapa indica que algumas regiões do município apresentam maior vulnerabilidade socioeconômica, sendo caracterizadas pela falta de infraestrutura adequada, enquanto outras apresentam melhores níveis socioeconômicos e acesso a uma infraestrutura urbana adequada.

O grupo 1 localiza-se nas proximidades de áreas de manguezal, enquanto o grupo 2 situa-se nas áreas marginais da cidade, ambos apresentando alta suscetibilidade à inundação. $\mathrm{O}$ grupo 3 é um aglomerado de bairros ao redor da área central e na porção leste do perímetro urbano, com a melhor renda média e que compreende o maior número de bairros. Os bairros do grupo 4 estão situados na porção oeste do município em áreas de planície de inundação dos rios Piraí e Cubatão e, o grupo 5 abrange uma parcela dos bairros localizados nas áreas marginais do perímetro urbano, com um aglomerado ao sul e outro ao norte, com destaque para as zonas industriais da cidade.

Os bairros pertencentes aos grupos 1, 2 e 4, contemplam 17 bairros e possuem alta tendência de ocorrência de doenças de veiculação hídrica, em função de características geomorfológicas, socioeconômicas, de planejamento e infraestrutura urbana. Paiva \& Souza (2018) constataram que as internações por doenças veiculadas pela água estão associadas às condições de saneamento básico e cobertura por serviços de atenção básica. Para esses bairros em especial, é sugerida a adoção integrada de políticas de saneamento, educação e assistência à saúde, que considerem as desigualdades locais, com a melhoria das condições de saúde da população e dos indicadores de saúde para as referidas doenças (PAIVA \& SOUZA, 2018; CALDAS et al., 2019).

Ressalta-se que os investimentos em saneamento contribuiriam, além da melhoria nas condições de saúde, para a redução do impacto da pobreza e das desigualdades nas comunidades mais vulneráveis (MOURA et al., 2010; ZIERO et al., 2016). 
Figura 7 - Mapa resultante da análise de agrupamento.

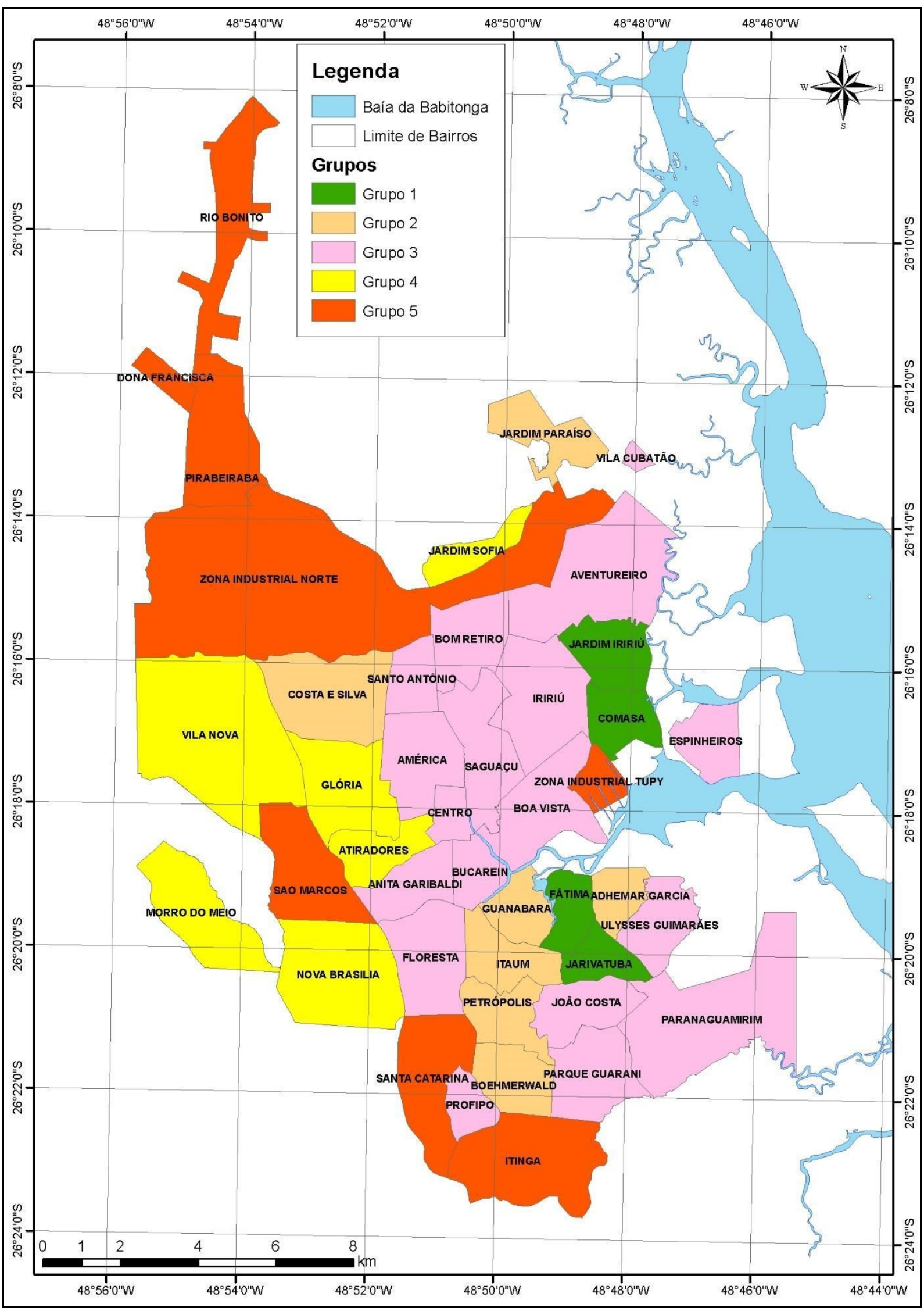




\section{CONCLUSÃO}

Como fechamento deste estudo constatou-se que as áreas de maior poder aquisitivo proporcionam melhores condições de moradia, com acesso à água potável e esgotamento sanitário. Áreas marginais com pouca infraestrutura tendem a ser densamente ocupadas por uma população de menor renda e expostas a processos de inundação e enfermidades de veiculação hídrica.

Em Joinville observou-se que existe uma relação entre cobertura de esgoto, renda média, inundação e densidade demográfica, que podem explicar a ocorrência da leptospirose no município. Os bairros com os maiores números de casos são de modo geral os que possuem a menor infraestrutura sanitária, as menores rendas, as maiores densidades demográficas e se localizam em áreas de risco à inundação. Já os bairros com os menores números de casos são os que possuem as menores densidades demográficas ou que dispõem de melhor infraestrutura sanitária e apresentam uma população de maior poder aquisitivo.

Os grupos formados permitiram identificar as áreas geográficas nas quais os moradores compartilham condições de vida semelhantes. Os grupos 1 e 2, que possuem os maiores números de casos, estão divididos entre áreas inundáveis próximas a manguezais, e regiões marginais da cidade, em planícies de inundação em áreas com pouca ou nenhuma infraestrutura sanitária, além da alta densidade demográfica, composta por famílias de baixa renda.

A caracterização desses locais é de extrema importância, já que possibilita a implementação de medidas estratégicas específicas para as demandas dessas populações, direcionando mais recursos para essas áreas e contribuindo para diminuir as desigualdades entre as regiões urbanas.

\section{REFERÊNCIAS}

BAILEY, T.C. Spatial statistical methods in health. Cadernos de Saúde Pública, v.17, n.5, p.1083-98, 2001. https://doi.org/10.1590/S0102-311X2001000500011

BRASIL. Ministério da Saúde. Secretaria de Vigilância em Saúde. Departamento de Vigilância das Doenças Transmissíveis. Leptospirose: diagnóstico e manejo clínico. Brasília: Ministério da Saúde, 2014.

CALDAS, J. P.; ALBUQUERQUE, H.; PRAÇA, H. L. F.; SIQUEIRA, A. S. P.; TOLEDO, L. M. DE; SABROZA, P. C. Análise espacial dos determinantes socioambientais para leptospirose no município de Itaboraí-RJ, através da abordagem ecossistêmica. Hygeia - Revista Brasileira de Geografia Médica e da Saúde, v. 15, n. 33, p. 42-53, 2019. https://doi.org/10.14393/Hygeia153351664

CAMPIOLI, P.; VIEIRA, C. V. Avaliação do Risco a Inundação na Bacia Hidrográfica do Rio Cubatão do Norte, Joinville/SC. Revista Brasileira de Geografia Física, v. 12, n.1, p. 1-17, 2019. https://doi.org/10.26848/rbgf.v12.1.p124-138

CARVALHO, C. B. C.; GOMES, M. L. C.; SANTOS, C. L.; RABELLO, R. S; THOMÉ, S. M. G. Leptospirose humana no estado do Rio de Janeiro: análise espaço-temporal e perfil dos casos confirmados no período de 2007 a 2014. REVA. Acad. Rev. Cient. da Saúde, v. 2, n.3, p. 10-22, 2017. https://doi.org/10.24118/reva1806.9495.2.3.2017:343

CESA, M. V.; DUARTE, G. M. A qualidade do ambiente e as doenças de veiculação hídrica. Geosul, v. 25, n. 49, p 63-78, 2010. https://doi.org/10.5007/2177-5230.2010v25n49p63

CHAIBLICH, J. V.; LIMA, M. L. S., OLIVEIRA, R. F.; MONKEN, M.; PENNA, M. L. F. Estudo espacial de riscos à leptospirose no município do Rio de Janeiro (RJ). Saúde Debate, v. 41, n. especial, p.225-240, 2017.

CHIARAVALLOTI-NETO, F. O geoprocessamento e saúde pública. Arquivos de Ciências da Saúde, [S.I.], v. 23, n. 4, p. 01-02, 2017. https://doi.org/10.17696/2318-3691.23.4.2016.661

COURA, J. R. Síntese das doenças infecciosas e parasitarias. Rio de Janeiro, ed. Guanabara Koogan, 2008.

FONSECA, J. S.; MARTINS, G. A. Curso de estatística. 6ª edição, São Paulo, Ed. Atlas S.A., 2012.

GENOVEZ, M.E. Leptospirose: uma doença de ocorrência além da época das chuvas! Biológico, v.71, n.1, p.1-3, 2009. 
GONÇALVES, N. V. et al. Distribuição espaço-temporal da leptospirose e fatores de risco em Belém, Pará, Brasil. Ciênc. saúde coletiva, Rio de Janeiro , v. 21, n. 12, p. 3947-3955, 2016. https://doi.org/10.1590/1413-812320152112.07022016

GUERRA, A. J. T.; CUNHA, S. B. da. Impactos Ambientais Urbanos no Brasil. 4 ed. Rio de Janeiro, Bertrand Brasil, 2006.

MELLO, Y. Distribuição de precipitação no município de Joinville (SC) e sua relação com a incidência de leptospirose. Dissertação (Mestrado em Saúde e Meio Ambiente), Universidade da Região de Joinville - UNIVILLE, Joinville, 2015. https://doi.org/10.21726/abc.v4i3.420

MELLO, Y. R.; SIMM, M.; VIEIRA, C. V. Características físicas da Bacia Hidrográfica do Rio Cachoeira, Joinville (SC). Acta Biológica Catarinense, v. 4, n. 3, p.5-17, 2017.

MOURA BLA, CUNHA RC, AQUINO R, MEDINA MG, MOTA ELA, MACINKO J, et al.. Principais causas de internação por condições sensíveis à atenção primária no Brasil: uma análise por faixa etária e região. Rev Bras Saúde Matern Infant., v. 10, p. 583-91, 2010. https://doi.org/10.1590/S1519-38292010000500008

OLIVEIRA, T. V. S.; MARINHO, D. P.; NETO, C. C.; KLIGERMAN, D. C. Variáveis climáticas, condições de vida e saúde da população: a leptospirose no Município do Rio de Janeiro de 1996 a 2009. Ciência e Saúde Coletiva, v. 17, n.6, p.1569-1576, 2012. https://doi.org/10.1590/S1413$\underline{81232012000600020}$

PAIVA, R. F.P. S.; SOUZA, M. F. P. Associação entre condições socioeconômicas, sanitárias e de atenção básica e a morbidade hospitalar por doenças de veiculação hídrica no Brasil. Cad. Saúde Pública, v. 34, n. 1, e00017316, 2018. https://doi.org/10.1590/0102-311x00017316

PAULA, E. V. Leptospirose Humana: uma análise climato-geográfica de sua manifestação no Brasil, Paraná e Curitiba. In: Anais XII Simpósio Brasileiro de Sensoriamento Remoto, Goiânia, Brasil, p. 2301-2308, 2005.

PELISSARI, D. M.; MAIA-ELKHOURY, A. N. S.; ARSKY, M. L. N. S.; NUNES, M. L. Revisão sistemática dos fatores associados à leptospirose no Brasil, 2000-2009. Epidemiol. Serv. Saúde, v.20, n.4, 2011. https://doi.org/10.5123/S1679-49742011000400016

SANTOS, N. J.; SOUSA, E.; REIS. M. G.; KO, A. I.; COSTA, F. Rat infestation associated with environmental deficiencies in an urban slum community with high risk of leptospirosis transmission. Cad. Saúde Pública, v. 33, n. 2, e00132115, 2017. https://doi.org/10.1590/0102-311x00132115

SEPUD. Secretaria de Planejamento Urbano e Desenvolvimento Sustentável de Joinville. Joinville bairro a bairro 2017. Joinville, 2017, 188 p. Disponível em: <https://www.joinville. sc.gov.br/wpcontent/uploads/2017/01/Joinville-Bairro-a-Bairro-2017.pdf>. Acesso em: 5 abr. 2018.

SILVEIRA, W. N. História das inundações de Joinville: 1851 - 2008. Wivian Nereida Silveira, Masato Kobiama, Roberto Fabris Goerl, Brigitte Brandenburg - Curitiba, Ed. Organic Trading, 2009.

SINAN. Sistema de Informação de Agravos de Notificação. Disponível em: <http://tabnet.datasus.gov.br/cgi/deftohtm.exe?sinannet/cnv/leptobr.def>. Acesso em: 18 set. 2018.

TEBALDI, M. Projeto mangue: urbanização, promoção social e preservação do meio ambiente. Joinville, Ed. Letradágua, 2008.

UHR, J. G. Z.; SCHMECHEL, M.; UHR, D. A. P. Relação entre saneamento básico no Brasil e saúde da população sob a ótica das internações hospitalares por doenças de veiculação hídrica. RACEF Revista de Administração, Contabilidade e Economia da Fundace. v. 7, n. 2, p. 01-16, 2016. https://doi.org/10.13059/racef.v7i2.104

VASCONCELOS, C. H.; FONSECA, F. R.; LISE, M. L.Z.; ARSKY, M. L. N. S. Fatores ambientais e socioeconômicos relacionados à distribuição de casos de leptospirose no Estado de Pernambuco, Brasil, 2001-2009. Cad. Saúde Colet., v.20, n.1, p.49-56, 2012.

VAVASSORI, A. C. "Cobertura de esgoto de Joinville será de $48 \%$ no próximo ano", diz presidente da Águas de Joinville. OCPNews. 11/09/2019. Disponível em: $<$ https://ocp.news/geral/cobertura-de-esgoto-de-joinville-sera-de-48-no-proximo-ano-diz-presidenteda-aguas-de-joinville>. Acesso em: 18/03/2020. 
APÊNDICE 1

\begin{tabular}{|c|c|c|c|c|c|}
\hline Bairro & $\begin{array}{c}\text { Casos } \\
(10 \text { anos })\end{array}$ & $\begin{array}{c}\% \text { de } \\
\text { Inundação }\end{array}$ & $\begin{array}{c}\% \text { de } \\
\text { Esgoto }\end{array}$ & $\begin{array}{c}\text { Renda Média } \\
\text { (salários } \\
\text { mínimos) }\end{array}$ & $\begin{array}{c}\text { Densidade } \\
\text { Demográfica } \\
(\text { hab/km²) }\end{array}$ \\
\hline Adhemar Garcia & 10 & 27,15 & 33,45 & 1,58 & 5.235 \\
\hline América & 6 & 38,43 & 94,72 & 5,74 & 2.742 \\
\hline Anita Garibaldi & 4 & 64,45 & 78,97 & 4,24 & 2.964 \\
\hline Atiradores & 1 & 10,42 & 29,04 & 6,46 & 1.967 \\
\hline Aventureiro & 30 & 25,70 & 0,00 & 1,57 & 4.090 \\
\hline Boa Vista & 23 & 24,10 & 0,00 & 2,03 & 3.428 \\
\hline Boehmerwald & 19 & 29,86 & 0,00 & 1,52 & 5.716 \\
\hline Bom Retiro & 8 & 21,60 & 42,93 & 2,92 & 3.332 \\
\hline Bucarein & 1 & 53,71 & 84,93 & 3,90 & 2.940 \\
\hline Centro & 1 & 83,65 & 99,55 & 6,36 & 4.176 \\
\hline Comasa & 13 & 58,96 & 0,00 & 1,52 & 7.981 \\
\hline Costa e Silva & 14 & 31,84 & 75,17 & 2,61 & 4.608 \\
\hline Dona Francisca & 2 & 8,81 & 0,00 & 1,96 & 531 \\
\hline Espinheiros & 6 & 13,14 & 60,01 & 1,52 & 3.365 \\
\hline Fátima & 25 & 76,12 & 11,87 & 1,40 & 7.006 \\
\hline Floresta & 15 & 23,15 & 21,79 & 2,42 & 3.981 \\
\hline Glória & 4 & 12,24 & 64,28 & 4,22 & 2.125 \\
\hline Guanabara & 4 & 40,74 & 29,33 & 2,07 & 4.916 \\
\hline Iririú & 13 & 14,43 & 9,56 & 2,12 & 3.970 \\
\hline Itaum & 19 & 33,36 & 42,90 & 1,77 & 4.968 \\
\hline Itinga & 16 & 16,64 & 0,00 & 1,45 & 910 \\
\hline Jardim Iririú & 14 & 39,18 & 0,00 & 1,52 & 7.622 \\
\hline Jardim Paraíso & 23 & 59,50 & 0,00 & 1,16 & 5.763 \\
\hline Jardim Sofia & 8 & 93,38 & 0,00 & 1,56 & 2.185 \\
\hline Jarivatuba & 16 & 13,92 & 0,00 & 1,41 & 6.527 \\
\hline João Costa & 9 & 22,92 & 0,00 & 1,52 & 4.071 \\
\hline Morro do Meio & 10 & 45,40 & 0,00 & 1,30 & 1.995 \\
\hline Nova Brasília & 4 & 25,95 & 8,04 & 1,68 & 1.803 \\
\hline Paranaguamirim & 24 & 23,22 & 0,00 & 1,17 & 2.663 \\
\hline Parque Guarani & 8 & 11,79 & 0,00 & 1,24 & 2.665 \\
\hline Petrópolis & 10 & 31,54 & 0,00 & 1,54 & 4.855 \\
\hline Pirabeiraba & 54 & 27,84 & 0,00 & 2,15 & 753 \\
\hline Profipo & 1 & 8,11 & 30,49 & 1,61 & 2.942 \\
\hline Rio Bonito & 7 & 2,71 & 0,00 & 1,49 & 1.203 \\
\hline Saguaçu & 8 & 26,59 & 72,79 & 3,60 & 2.959 \\
\hline Santa Catarina & 5 & 0,86 & 4,34 & 1,67 & 1.235 \\
\hline Santo Antônio & 3 & 52,70 & 82,78 & 3,96 & 3.294 \\
\hline São Marcos & 1 & 17,90 & 3,74 & 2,29 & 536 \\
\hline Ulysses Guimaraes & 3 & 36,95 & 7,42 & 1,14 & 3.204 \\
\hline Vila Cubatão & 4 & 18,66 & 0,00 & 1,48 & 3.042 \\
\hline Vila Nova & 46 & 36,75 & 0,00 & 1,76 & 1.685 \\
\hline Zona Industrial Norte & 1 & 31,74 & 2,41 & 1,39 & 113 \\
\hline Zona Industrial Tupy & 0 & 14,70 & 0,00 & 1,73 & 48 \\
\hline
\end{tabular}

